\title{
A dimensão estética e democrática da experiência: uma contribuição da filosofia deweyana para novas propostas educacionais
}

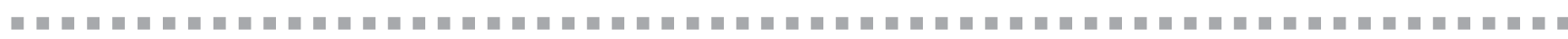
Cecília Maria Siqueira Silva

\section{Resumo}

A continuidade entre experiência e conhecimento, ação e reflexão, indivíduo e sociedade são os fundamentos da concepção de educação na filosofia deweyana que trazem sentido para este nosso questionamento da prática pedagógica e suas relações com a arte. Analisar a educação como reconstrução contínua da experiência e pensar nos pressupostos do hábito inteligente e cooperativo de julgamento nos faz compreender melhor a função democratizante que a perspectiva deweyana traz às propostas educativas. A reflexão sobre as qualidades educativas da experiência estética nos possibilita ainda, no viés desta filosofia, compreender as necessidades e condições essenciais sobre as quais devem ser desenvolvidas essas propostas.

Palavras-chave: experiência estética; educação democrática; reconstrução da experiência; participação social.

\begin{abstract}
The esthetic and democratic dimension of the experience: a contribution of Dewey's philosophy for new educational proposals

Continuity between experience and knowledge, action and reflection, individual and society are the key elements of the education conception according to Dewey's philosophy, which brings meaning to our questioning on pedagogical practices and their relationships with art. Analyzing education as the continuous reconstruction of experience and thinking on the premises of intelligent and cooperative habit for judging lead to a better understanding of the democratizing role, which are brought to educational proposals by Dewey's perspective. Reflection on the educational qualities of esthetic experience allows, as an additional consequence of this philosophy, the understanding of the needs and essential conditions for the proper development of such proposals.
\end{abstract}

Keywords: esthetic experience; democratic education; experience reconstruction; social participation. 


\section{Introdução}

Que a arte ocupa lugar de destaque nas atuais propostas curriculares - por sua reconhecida função social e qualidade educativa - é fato que não mais se questiona. No entanto, o êxito destas propostas mostra-se ainda ameaçado quando o professor lida com a arte, na escola, como algo que pode ser simplesmente agregado às demais disciplinas, um meio simplesmente facilitador da aprendizagem, ou ainda um mero atrativo para o currículo. A ausência de uma fundamentação que possa realmente explicitar as íntimas relações entre a arte e a educação talvez seja o problema que, atualmente, mais sobrecarrega esta prática educativa de incertezas e incoerências.

O desenvolvimento de uma prática educativa que tenha coerência e compromisso com estas propostas - uma prática realmente enriquecida com as possibilidades da arte - requer uma atividade permanente de investigação sobre os princípios e fundamentos que as constituem, o que vai possibilitar ao educador ajustar e reelaborar, com autonomia, procedimentos e métodos, para as circunstâncias reais em que se encontra, com as suas condições próprias e específicas. A pesquisa e o aprofundamento teórico em educação, acompanhando o desenvolvimento das práticas pedagógicas, favorecem esta autonomia do educador, mantendo sempre vivos alguns questionamentos: de que forma a arte, na educação, pode favorecer a integração das áreas de conhecimento? Por que está o fazer artístico implicado com o desenvolvimento da capacidade de interpretação da realidade? De que forma a educação estética está comprometida com a moralidade?

No sentido de aprofundar estes questionamentos, podemos encontrar na filosofia de John Dewey uma importante contribuição que, certamente, nos apontará caminhos para um melhor aproveitamento das qualidades educativas da arte. Assim, a análise das relações entre a arte, a educação e a experiência democrática, na filosofia deweyana, consiste em uma tentativa de fortalecer esta fundamentação, oferecendo possibilidades de uma prática educativa realmente imbuída dos princípios estéticos e comprometida com um modo de vida social cooperativo e participativo.
Nesta análise, o conceito de inteligência é compreendido como o instrumento da participação social, em outras palavras, como a própria qualidade da ação quando permeada pela reflexão e capacidade de interpretação de uma circunstância vivida. Nesta perspectiva, a experiência destituída de pensamento reflexivo afasta-se da condição inteligente, para se constituir uma prática mecânica, esvaziada do caráter e intenção social. É, pois, objeto desta análise a contribuição deweyana para focar as condições, na educação, favoráveis ao desenvolvimento do hábito inteligente e cooperativo, assim como as implicações da arte neste processo.

\section{As qualidades educativas da arte: repensando a prática pedagógica}

Ao definir a educação como contínua reconstrução da experiência social, Dewey põe em relevo a atividade de pensamento como mecanismo fundamental deste processo, evidenciando o eixo principal de uma pesquisa e proposta educacional providas de qualidade social. Considerar as expressões deweyanas como "aprender a pensar" ou "aprender a aprender" significa reconhecer o princípio de reelaboração da experiência como base da prática educativa e, desta forma, compreender o conhecimento como sua manifestação, permanentemente reconstituído e reavaliado. O mecanismo de revisão e reelaboração da própria prática educativa, em situações de cooperação e compartilhamento de diferentes interesses e opiniões, confere ao ambiente escolar o caráter próprio da vida social, favorável ao desenvolvimento da capacidade de resolver problemas, verificar, na prática, hipóteses, julgar e discernir idéias e valores um convívio participativo baseado no método da inteligência cooperativa, para Dewey o pressuposto da contínua reconstrução da experiência social. É com base nestes fundamentos deweyanos que propomos questionar as condições para o desenvolvimento deste hábito inteligente e cooperativo na escola e, também, as possibilidades da arte como experiência educativa.

A arte, na filosofia deweyana, corresponde a uma experiência intensa e inteligente que compreende a atividade do 
pensamento na reelaboração de conceitos, valores ou hábitos; uma experiência de grande valor educativo pelo uso da inteligência que implica e pela possibilidade que oferece de compartilhamento de idéias e sentimentos. O nosso propósito consiste, assim, em analisar as relações entre a arte e a educação, já que, para Dewey, este processo de reelaboração da experiência constitui a base do conhecimento, e a cooperação, a base da moralidade: a aprendizagem compreendida como reconstrução da experiência e a moralidade como crescimento pressupõem uma concepção de educação baseada no valor da participação. É por isto que a dimensão estética da experiência está estreitamente relacionada com a dimensão democrática: as qualidades estéticas são responsáveis pela contínua reelaboração da experiência, sendo que somente nesta condição criativa e participativa em que as atividades sociais são permanentemente avaliadas e reelaboradas é que se faz possível, para Dewey, o ideal democrático.

Encontrar um eixo que norteie um projeto educativo de caráter estético e democrático é tarefa básica nas propostas educativas que defendem a cooperação e participação efetivas nas atividades escolares. Neste sentido, as atividades expressivas - aquelas sustentadas pelas linguagens artísticas - oferecem um campo rico de possibilidades nas quais a realidade social pode ser manipulada, ou melhor, aproximada do trabalho educativo e vivenciada pelas crianças. Um jogo, brincadeira, atividades plásticas ou musicais são exemplos de atividades que podem aproximar a criança de um objeto de estudo e criar condições para uma aprendizagem significativa. Quais seriam, então, as qualidades educativas compreendidas neste tipo de atividade?

Os pressupostos deweyanos de continuidade entre vida e educação, experiência e conhecimento, escola e sociedade revelam a sua crença na utilidade prática do conhecimento e na função social da educação. A arte, como experiência, mostra-se comprometida com estes pressupostos pelas qualidades que apresenta: o envolvimento completo da criança nas atividades estéticas com suas potencialidades intelectuais, imaginativas e emotivas; a possibilidade de seleção e ordenação de significados sociais de acordo com as experiências vividas; a presença de obstáculos e situações de conflito que reproduzem a vida social; o mecanismo de ação e percepção receptiva no desenvolvimento da experiência e a continuidade entre meios e fins na atividade - estas seriam, para Dewey, algumas qualidades educativas da arte, já que estão comprometidas com o desenvolvimento da capacidade de pensar, socializar a experiência e utilizar significativamente os conhecimentos.

É comum verificarmos, em muitas práticas educativas, uma extrema valorização da capacidade intelectiva e memorização em detrimento da capacidade de percepção, interpretação, habilidades manuais ou associações analógicas a marca, ainda profunda, da educação tradicional persiste nessas práticas no sentido de separar as atividades perceptivas das intelectuais, as atividades do corpo e da mente, as atividades racionais e aquelas que envolvem a emoção e a imaginação. Estaria a arte envolvida neste compromisso de amenizar estas rupturas? As atividades expressivas, ou seja, aquelas que compreendem qualidades estéticas, são, para Dewey, essencialmente educativas, justamente por considerar a unidade entre estas atividades e, dessa forma, promover não o desenvolvimento de habilidades isoladas e desarticuladas da própria experiência, mas sim o desenvolvimento da criança de acordo com as possibilidades sociais, segundo Dewey (1944, p. 15), "traduzindo seus instintos e tendências em equivalentes sociais". Neste sentido, a arte corresponde a uma experiência real e verdadeira, pois pode articular as diferentes potencialidades da criança em uma mesma atividade, e é também considerada uma experiência educativa, por promover o desenvolvimento de capacidades em atividades providas de qualidade social.

\section{Educacão como reconstrução da experiência social: a contribuição deweyana}

A concepção deweyana de educação como reconstrução da experiência social nos faz pensar a prática pedagógica em sua dinâmica própria de elaboração pessoal e coletiva. O que nos propomos neste artigo é investigar as formas e os fundamentos desta dinâmica, ou seja, as formas mais adequadas para que o processo 
do conhecimento alcance um caráter criativo e cooperativo. Neste sentido, é importante destacar que a possibilidade de seleção e ordenação de significados consiste em outra importante qualidade educativa da experiência estética: trata-se de um processo no qual os significados são determinados pelas relações que eles mantêm entre si e para com as emoções e conceitos já incorporados. Compreender este processo de seleção e ordenação de significados na experiência estética é importante no sentido em que evidencia certas condições básicas e essenciais para o processo de conhecimento: a aquisição de conhecimentos pode ser entendida como um processo no qual um novo significado é conectado a um conjunto de idéias já constituídas e inter-relacionadas. Perceber as relações entre uma idéia nova para com os outros significados já incorporados pelo indivíduo consiste num dos aspectos básicos da aprendizagem, e a emoção tem um importante papel neste processo, porque cobre de sentido a atividade, além de oferecer uma orientação às ações, de acordo com as preferências e os interesses da criança. Para Dewey (1959, p. 215), não adianta uma atividade querer despertar o interesse da criança apenas por meio de distrações e divertimentos:

Já se sabe que, se a atividade não fizer uso das emoções e dos desejos, se não oferecer uma válvula para a energia que tenha algum significado para o próprio indivíduo, seu espírito dela se afastará com aversão, embora externamente nela se conserve.

Com essa afirmação, Dewey lembra da importância de se considerar as habilidades pessoais da criança como as bases do conhecimento, compreendendo as emoções e as potencialidades imaginativas, ao lado das faculdades intelectuais em todo processo educativo. Uma vez que as qualidades estéticas em educação possibilitam a integração das diferentes habilidades e diversas potencialidades da criança e, também, o desenvolvimento da sensibilidade para uma efetiva reflexão sobre os problemas e conceitos abordados, podemos considerar a arte um importante instrumento pedagógico e um meio adequado para os fins de formação pessoal e social.

Outro fator para o crescente desinteresse da criança para com o processo educativo e a instituição escolar consiste, muitas vezes, na ausência de um objetivo comum que possa dar um sentido e uma orientação às várias atividades escolares. Esta ruptura entre as ações e os próprios objetivos destas ações revela-se, muitas vezes, pela falta de um eixo orientador que ofereça um caráter cooperativo e um sentido comum às várias etapas de uma atividade ou mesmo às diversas matérias de estudo. É comum verificarmos um grande isolamento, um distanciamento entre as matérias como a matemática, a história e a literatura, por exemplo, sendo que isto pode acontecer mesmo no interior de cada matéria, quando os assuntos não são relacionados uns com os outros e, também, não são contextualizados histórica e socialmente. Desta forma, a criança tem a impressão de estar na frente de um amontoado de informações, sem conexões entre si e sem uma ordem que faça sentido para ela, porque não teve a oportunidade de participar na elaboração de hipóteses explicativas para fenômenos observados e não foi incentivada a elaborar os critérios segundo os quais o conhecimento poderia estar organizado. Estas condições de ensino não correspondem àquelas situações que instigam o uso da inteligência para a resolução de problemas; pelo contrário, mostramse inacessíveis e desestimulantes, justamente porque não convidam a criança a participar do processo educativo com a sua curiosidade e questionamento pessoal.

A descontinuidade entre meios e fins nas atividades educativas pode torná-las enfadonhas e desinteressantes (Dewey, 1949) para a criança, principalmente quando é marcada pela ausência de um objetivo que perpassa todos os processos da atividade ou ausência de um tema central que compreenda as diferentes áreas do conhecimento. Nestas condições, estes processos tornam-se mecânicos, desvinculados uns dos outros e do objetivo principal da atividade, o que nos faz questionar toda proposta educativa que não compreende o diálogo e planejamento cooperativo das diferentes áreas do conhecimento.

A desarticulação entre as atividades e entre estas e os seus objetivos acontece ainda em propostas educativas de caráter tradicionalista. Para compreendermos a importância da continuidade entre meios e fins de uma atividade, apontamos como modelo a experiência estética, que na filosofia deweyana é caracterizada por uma 
íntima conexão entre suas partes. Quando os vários momentos de uma obra de arte revelam esta conexão, então é possível perceber um jogo de correlações entre diferentes qualidades intrínsecas à experiência como um todo. Dewey (1949, p. 158) observa que é esta continuidade que confere à obra de arte uma essência de vida:

[...] quando obtemos de um produto artístico o sentimento de estarmos envolvidos com um processo, com uma história, percebida em um ponto particular de seu desenvolvimento, é quando temos a impressão de vida. O que está morto não se estende ao passado nem desperta nenhum interesse no porvir.

As diferentes partes no desenvolvimento de uma experiência estética têm como base comum um tema ou objetivo que as conecta e orienta - estão, na verdade, conectadas umas às outras, de forma a se completarem de sentido. Podemos analisar a importância da conexão entre as várias partes ou componentes de uma experiência em dois aspectos diferentes: no que se refere ao desenvolvimento ativo da experiência e, também, no que se refere à compreensão ou percepção do jogo de interações entre as suas partes. Em outras palavras, estes aspectos correspondem ao processo ativo de construção da obra, e o outro, ao processo de percepção receptiva.

Podemos ter como base para essa análise a experiência reflexiva, ou seja, quanto ao primeiro aspecto, sobre o desenvolvimento ativo da experiência, podemos pensar que uma idéia sempre tem como apoio uma outra idéia já formada, isto porque, no pensamento deweyano, as partes de um pensamento vão se encadeando umas às outras, de forma que uma dá sustentação à outra na construção de um novo conceito. O que nos importa verificar com este pressuposto é que as experiências presentes se apóiam nas antecessoras, aproveitando significados, valores e ideais em novas situações.

A continuidade entre meios e fins na experiência, que defendemos como fator de conexão entre suas várias fases, é importante na experiência educativa, também no sentido de considerar os saberes da criança e o modo como ela vai elaborar suas relações de sentido para um planejamento mais adequado das atividades escolares. $\mathrm{O}$ outro aspecto a ser analisado refere-se à maneira como é compreendida e percebida uma experiência: nas relações entre as suas partes. Fazendo um paralelo com a atividade educativa, podemos comparar esta capacidade de percepção em uma experiência estética à capacidade de correlação de significados entre as diferentes áreas de conhecimento. A presença de um tema central ou de um objetivo é, neste aspecto, essencial para a compreensão das várias partes como um todo. Este tema central ou objetivo que pode correlacionar as diferentes áreas de conhecimento tem, na perspectiva deweyana, um sentido pragmático, restabelecendo a continuidade entre a atividade educativa e a vida social.

É importante salientar que uma matéria de estudo deve ser compreendida em seu contexto de relações com as outras áreas do conhecimento. Este contexto de relações é definido, por sua vez, pelo objetivo ou tema central que é utilizado para o desenvolvimento da atividade educativa, isto é, dependendo do tema escolhido para orientar a atividade, as matérias de estudo podem ser relacionadas de diferentes formas. O que importa é que haja, sempre, este inter-relacionamento entre as diferentes áreas do conhecimento e que isto seja resultado da presença de temas ou objetivos de ordem social. Não existe sentido na separação absoluta entre as várias matérias de ensino, porque os conhecimentos, apartados de um tema significativo e social, não passam de uma simples informação, sem interesse para a criança e sem a possibilidade de contribuição moral. É neste sentido que a idéia de interdisciplinaridade, como o encontro e diálogo entre as matérias de estudo, constitui um fator de continuidade entre a vida e a educação.

Nesta perspectiva, as atividades escolares deveriam compreender situações e problemas vividos socialmente, de modo que a transferência destes problemas para o âmbito escolar possibilitasse sua compreensão e análise em seus vários aspectos que, na verdade, interagem entre si fazendo parte de um mesmo fenômeno. A separação destes aspectos é, de fato, artificial e prejudica a compreensão de qualquer situação pela criança, já que as informações transmitidas deixam muitas vezes de lado o seu caráter moral, ou seja, o modo pelo qual podemos transformar as ações com a análise de uma circunstância social. A continuidade entre as atividades escolares e a vida social é um dos pontos 
essenciais da filosofia deweyana, o que podemos entender como sugestão a idéia de que as matérias de ensino devem ter relação com a vida social e, ainda, observar que é justamente esta finalidade social que proporciona uma verdadeira unidade para processo do conhecimento.

\section{A continuidade da experiência como interdisciplinaridade na escola}

Verificamos que a idéia de interdisciplinaridade, na filosofia deweyana, corresponde à idéia de que a conexão entre as matérias de ensino se dá nas próprias atividades da criança quando são providas de caráter social. Nesta perspectiva, as atividades escolares deveriam refletir a vida social, justamente porque esta revela os fatos e situações em sua totalidade de aspectos, contínuos entre si - moral, afetivo, intelectivo, imaginativo -, dimensões de um todo, de uma determinada realidade vivida. Como aponta Dewey, um dos grandes erros da atividade escolar consiste no trabalho com uma grande quantidade de estudos especiais, sem uma relação direta e significativa com a vida social. Como forma de vencer estas dificuldades, jogos, brincadeiras e outras atividades de caráter lúdico são mencionados por Dewey como atividades que preparam a criança para o contato com as matérias formais.

Podemos relacionar este preparo com o desenvolvimento das capacidades e interesses da criança em situações construtivas, nas quais os desafios permitem a reflexão sobre os problemas propostos. A percepção das relações entre as diferentes áreas de conhecimento de sua atividade é uma qualidade própria das experiências que recorrem ao cotidiano da criança e às situações revestidas de caráter social e lúdico. Dewey salienta que esta continuidade constitui uma importante qualidade educativa devido à sua função "catalisadora" da experiência, ou seja, à sua propriedade de revelar as íntimas relações entre as suas partes, o que a torna um todo de realidade, permeado de sentido. Na experiência educativa, essa qualidade torna-se especialmente importante, porque proporciona à criança o exercício de correlação entre os aspectos diferentes que compõem um mesmo dado da realidade e, dessa forma, a possibilidade de compreensão de sua totalidade na relação com a vida social e cotidiana.

Vimos que a continuidade entre meios e fins, em uma experiência, constitui uma importante qualidade educativa que não corresponde a uma ligação rígida entre os meios e os fins da experiência, mas sim a uma relação flexível por meio da qual podese verificar uma contínua mudança nos objetivos e procedimentos. Em uma atividade educativa, a flexibilidade em seus processos e as mudanças dos objetivos a serem alcançados constituem aspectos positivos para a aprendizagem. Estas mudanças refletem a atitude reflexiva da criança na atividade, porque, quando existe pensamento, interesses e capacidades em ação, é natural que novos objetivos sejam construídos. Do contrário, quando não existe esta flexibilidade e possibilidade de mudança nos processos e objetivos de uma atividade, ficamos com uma experiência controlada, imposta, sem a participação real - e inteligente - da criança. Isso é comum acontecer nas atividades educativas que separam a prática da teoria, a ação da reflexão.

A experiência verdadeiramente educativa compreende a participação ativa da criança, com sua ação e reflexão; portanto, o planejamento das atividades educativas deve ser construído de forma a considerar essa participação ativa da criança e suas capacidades de construção e pensamento. As mudanças nos processos e objetivos de uma experiência são produtos de sua ação inteligente, e para compreendermos os fatores envolvidos nessas mudanças adotaremos novamente a experiência estética como modelo de análise. A experiência estética compreende uma atividade inteligente intensa e, por isso, é considerada por Dewey uma experiência verdadeira que possibilita sua permanente reelaboração. Justamente por compreender esta possibilidade de permanente reelaboração, em outras palavras, por ser flexível e aberta a uma permanente avaliação, é que a experiência estética é considerada essencialmente democrática.

Em uma experiência, a multiplicidade e variedade de elementos - significados e qualidades - é condição básica para que se propague o movimento de interação: oposição, acúmulo, conservação e cooperação. Dewey qualifica esta interação como uma atividade cooperativa de significados, 
responsável pela unidade da experiência no processo de percepção. Neste sentido, quando ocorre o movimento de repulsa e divergência entre alguns elementos da experiência, é necessário que haja um momento de análise e conciliação no qual esses elementos encontram uma forma compensadora de interação. Na experiência estética, a percepção unificada de uma obra de arte deve compreender todo este trabalho de interação entre os seus significados e qualidades, não esquecendo que esta interação também compreende os significados e as sensações próprias do indivíduo de experiências anteriores.

A experiência estética compreende uma atividade humana intensa - atividade inteligente, denominada por Dewey (1949, p.85) de processo de percepção receptiva -, em que a emoção “evoca, reúne, aceita e afasta recordações, imagens, observações e as elabora em uma totalidade entonada por todas as partes com o mesmo sentimento emocional imediato”. Esta capacidade de criar uma interação entre significados diversos de uma experiência ou de constituir a unidade ante a multiplicidade por meio desta interação é o que estabelece a continuidade entre experiência estética e educativa. A experiência educativa deve ter como base o exercício de correlação entre uma multiplicidade de significados - por meio da ação e percepção receptiva -, o que corresponde a uma análise comparativa entre esses diferentes significados. Analisar comparativamente compreende, no entanto, a relação entre significados intelectuais assim como entre qualidades sensíveis inerentes a um determinado objeto de conhecimento e ao sistema global de objetos conectados ${ }^{1}$ do indivíduo que vive a experiência.

A partir destes fundamentos, podemos, então, nos questionar sobre os modos mais adequados da prática educativa para que seja alcançada esta correlação entre as várias partes de uma experiência, em outras palavras, para que tenha êxito o que denominamos, hoje, de interdisciplinaridade. O trabalho com as informações abordadas na escola pode ter qualidade verdadeiramente educativa quando promove a reflexão e, por meio desta, a compreensão de seu sentido dentro de temas sociais. As atividades expressivas ou construtivas, para Dewey, cumprem este papel ao propiciar o questionamento, a investigação e a experimentação em situações de caráter social, ou seja, contextos verdadeiramente significativos para a criança.

\section{A unidade da experiência educativa e a utilidade do conhecimento: quando a acão encontra as possibilidades da reflexão}

Em teoria estética, dizer que a unidade na experiência é dinâmica, ou seja, que a obra de arte é produto da interação entre uma multiplicidade de elementos simbólicos, corresponde, no que se refere à educação, a dizer que o conhecimento é produto da atividade inteligente do indivíduo, que se desenvolve por meio deste exercício de correlação entre significados e qualidades sensíveis - o que é intrínseco à experiência estética. Este trabalho de correlação entre os significados, no pensamento reflexivo, pressupõe a continuidade do indivíduo em seu meio social, ou seja, uma interação por meio da qual os conhecimentos possam ser verificados na experiência. Esta interação compreende a ação do indivíduo, de forma inteligente e planejada.

Contudo, o que vemos na maioria das escolas, atualmente, é a execução de tarefas mecânicas, sem qualquer vínculo com a vida prática e social. A descontinuidade entre as atividades práticas e o pensamento reflexivo é uma característica marcante de nossa experiência social cotidiana e, especialmente, da experiência educativa. Considerar o pensamento humano como um estoque de informações, com a função reduzida à assimilação passiva do que lhe é imposto, ignorando as interações com o meio social, constitui, para Dewey, o erro que sustenta todo o fracasso da escola como instituição social. Técnica e superficial torna-se a relação com o conhecimento o que, para Dewey, não compreende o verdadeiro crescimento.

Uma vez que a interação ao meio social compreende a ação inteligente, podemos considerar que a condição básica para a atividade e formação do pensamento são as próprias respostas decorrentes das ações do indivíduo em seu meio como elementos orientadores de seu pensamento e, assim, do curso de sua experiência. Na filosofia deweyana, a percepção da realidade não corresponde a um processo passivo, de assimilação de fatos e idéias, mas sim

\footnotetext{
Dewey (1949) denomina de sistema global de objetos conectados o conjunto de significados armazenados pelo indivíduo, decorrentes de suas diversas experiências de vida.
} 
a um processo ativo, no qual as reações como resultados das interferências do indivíduo em seu meio - são os elementos constitutivos do pensamento.

O conhecimento só é verdadeiro e significativo, para Dewey, quando formulado pela "adaptação do estímulo sensorial e da reação motriz” (Dewey, 1954, p. 143). É a utilidade do conhecimento, no curso de uma ação, que constitui a sua veracidade e o seu valor significativo - daí a importância de sua correspondência à vida social. A utilização do conhecimento nas atividades práticas possibilita a sua verificação, ou seja, possibilita compreender se ele é coerente com os resultados obtidos em determinada experiência. Esta verificação é de grande valia para a continuidade da experiência, porque faz que o indivíduo avalie a utilidade e veracidade deste conhecimento e, com base neste julgamento, possa reelaborar conceitos, valores e procedimentos práticos. Para que a atividade seja contínua, isto é, compreenda esta reelaboração de idéias, é preciso que exista um motivo que anime o processo no desenvolvimento da atividade. Este motivo, ou propósito, nasce de uma identificação do indivíduo com algum aspecto desta atividade - o sentido social - e é o que impulsiona o indivíduo para a ação.

Além do motivo social que impulsiona a ação, Dewey aponta a necessidade de um esforço para esta reelaboração de idéias - a criação de novos meios e objetivos, no planejamento da atividade. A atividade do pensamento para esta criação de novos planos de ação exige concentração, perseverança, retitude e sinceridade ${ }^{2}$ - é um trabalho que exige esforço. Dewey (1954, p. 128) observa sobre a importância do esforço - na atividade do pensamento -, no curso de uma ação, utilizando o exemplo de um menino que deseja fazer um papagaio:

No curso das operações, dificuldades inesperadas o assaltam [...] examina as razões porque o seu trabalho não está certo, e estuda, e compara, e procura novos meios e novos remédios. À medida que assim procede, o seu pensamento a respeito do papagaio como um todo se torna mais nítido, o seu projeto se torna mais claro e os meios de realizá-lo mais adequados.

Nas atividades educativas, a teoria não pode estar desvinculada da prática justamente porque a atividade do pensamento é estimulada pelas dificuldades encontradas no curso de uma atividade. A ação prática da criança em uma atividade provê as reações necessárias para que haja uma adaptação dos atos aos novos objetivos. $\mathrm{Na}$ arte, esta adaptação entre os atos e o pensamento ou, então, entre a ação e a percepção receptiva é um processo permanente e intenso. A percepção receptiva corresponde a esta atividade do pensamento, por meio da qual o indivíduo organiza suas idéias, desejos e propósitos, na interação com algum aspecto da realidade vivida. É nessa interação com o meio que são produzidas as reações com as quais será realizada esta organização - que é a percepção receptiva. A continuidade entre a ação e a percepção está presente tanto no fazer artístico como na apreciação estética, daí que as atividades construtivas desenvolvidas com a criança não devem se limitar às práticas, mas devem também contemplar toda forma de percepção sensível na relação com as diferentes linguagens artísticas.

O prazer no desenvolvimento de uma atividade e a satisfação objetiva na conclusão de um trabalho correspondem à realização dos propósitos compreendidos em uma experiência, mas em situações nas quais as ações das crianças se perdem e não encontram respostas, situações nas quais não se pode avaliar e apreciar o que foi feito, esta possibilidade de realização é perdida. A ação e a percepção receptiva, como processos contínuos, que constituem toda experiência estética, são fontes de satisfação que recobrem a prática educativa de sentido, dinamismo e criação.

A continuidade entre a ação e a percepção receptiva é uma qualidade estética da experiência que corresponde a um envolvimento integral do indivíduo na experiência - intelectual, imaginativo e emotivo -, o que vai possibilitar à criança reelaborar os seus atos de forma criativa, dando continuidade à experiência. Estamos falando de uma postura avaliativa que tanto a criança como o professor devem adotar para o desenvolvimento criativo de uma atividade.

Esta continuidade entre a ação e a percepção receptiva na arte deve estar presente nas atividades educativas, como continuidade entre ação e reflexão ou entre a experiência prática e pensamento imaginativo, justamente por ser uma condição básica da continuidade da experiência, ou 
seja, de sua permanente avaliação e reelaboração. Para que a criança possa avaliar e planejar de forma inteligente sua experiência, é preciso que haja atividade do pensamento na verificação da utilidade de certas idéias na prática, para que sejam reelaboradas e, assim, adaptadas a novos objetivos. As qualidades estéticas até aqui analisadas são as condições básicas para esta atividade inteligente: a continuidade entre as faculdades intelectuais, emotivas e imaginativas, a continuidade entre meios e fins, a interação entre os elementos significativos na experiência e a continuidade entre ação e percepção receptiva. Podemos dizer que, para Dewey, as atividades estéticas são essencialmente educativas, justamente porque compreendem essas continuidades e oferecem à escola a possibilidade de uma vivência real das circunstâncias sociais, e uma vivência democrática, porque compreendem a participação inteligente e são carregadas de sentido e caráter moral.

\section{Conclusão}

A arte, na filosofia deweyana, corresponde a uma experiência intensa e inteligente, compreendendo a atividade do pensamento imaginativo na recriação e reordenação de significados vivenciados, na qual os significados são socializados, apresentando-se de uma forma unificada. Concluímos que a experiência estética tem um grande valor educativo, pelo uso da inteligência que implica e pela comunicação de significados sociais, como força unificadora.

A educação, na filosofia deweyana, como a contínua reconstrução da experiência, encontra os seus meios e fins na própria vida social, o que lhe confere o sentido de pragmática. Promovendo a continuidade entre o indivíduo e o meio social, ação e reflexão, teoria e prática, a educação deweyana objetiva o desenvolvimento do hábito inteligente - o hábito de pensar, aprender a pensar ou aprender a aprender (Dewey, 1959). Dessa forma, as atividades construtivas de caráter lúdico e estético são apresentadas neste artigo como a possibilidade de desenvolvimento de propostas educacionais comprometidas com a participação criativa da criança em sua avaliação e planejamento.

Concluímos, também, pela necessidade de que os interesses e habilidades da criança possam ser reconhecidos como capacidades para alguma forma de contribuição em atividades sociais. Se acreditamos que a educação é o meio pelo qual se constitui esta continuidade entre o indivíduo e seu meio social, é preciso investirmos nesta idéia de comunicação entre a escola e a comunidade, entre o conhecimento e a experiência social. Esta continuidade fundamenta o pragmatismo deweyano e reveste a educação com uma função democratizante, o que evidencia mais uma vez a necessidade de uma organização escolar pautada nos valores da participação, tolerância e cooperação.

\section{Referências bibliográficas}

AMARAL, Maria Nazaré de C. Pacheco. Dewey: filosofia e experiência democrática. São Paulo: Perspectiva, 1990. (Coleção Debates ; 229).

n. 2, 1976

John Dewey: uma lógica da democracia. Revista da FEUSP, São Paulo, v. 2 ,

BARBOSA, Ana Mae T. B. Recorte e colagem: influência de John Dewey no ensino da arte no Brasil. São Paulo: Cortez, 1982.

DEWEY, John. El arte como experiência. México: Fondo de Cultura Económica, 1949.

El niño y el programa escolar: mi credo pedagógico. Trad. L. Luzuriaga. Buenos Aires: Losada, 1944.

. Como pensamos: como se relaciona o pensamento reflexivo com o processo educativo - uma reexposição. Trad. Haydée de Camargo Campos. São Paulo: Ed. Nacional, 1959. 
BARBOSA, Ana Mae T. B. Democracia e educação: breve tratado de Filosofia da Educação. Trad. G. Rangel e A. Teixeira. São Paulo: Ed. Nacional, 1936.

McDERMOTT, J. J. The philosophy of John Dewey. Chicago: The University of Chicago Press, 1981.

RYAN, Alan. John Dewey and the High Tide of American Liberalism. New York: Norton, 1995.

STROH, Guy W. American Philosophy from Edwards to Dewey: an introduction. Princeton: D. Van Nostrand Company, Inc., 1968.

Cecília Maria Siqueira Silva, mestre e doutora em Filosofia da Educação pela Faculdade de Educação da Universidade de São Paulo (Feusp), é professora do curso de Pedagogia da Faculdade Taboão da Serra (FTS).

cecisiqueira@zipmail.com.br

Recebido em 30 de março de 2006.

Aprovado em 11 de setembro de 2006. 